\title{
A NOTE ABOUT THE AUTHOR
}

Milton Silverman, Ph.D., born in San Francisco in 1910, was trained in biochemistry and pharmacology at Stanford University and the University of California School of Medicine.

From 1934 to 1959, he won national recognition as science editor of the San Francisco Chronicle, and later as a science writer for the Saturday Evening Post, Collier's, Reader's Digest, and other magazines. He is a past-president of the National Association of Science Writers and a winner of the Lasker Award for distinguished medical reporting.

His own research has included studies on synthetic sugars, anesthetics, the pharmacology of alcoholic beverages, and cultural drinking patterns in South America, Europe, and the United States. For nearly a decade, he has been deeply involved in research on the discovery, production, promotion, pricing, prescribing, and use and misuse of prescription drugs. He has acted as a consultant to the U.S. Public Health Service and, on drug insurance policies, to the Social Security Administration and the House Ways and Means Committee.

From 1966 to 1969 , he served as a special assistant to Philip R. Lee, M.D., Assistant Secretary for Health, in the Department of Health, Education, and Welfare, and as executive secretary of the HEW Task Force on Prescription Drugs. Since 1972, he has been a lecturer in pharmacology at the University of California's Schools of Pharmacy and Medicine in San Francisco, and a senior faculty member in UCSF's Health Policy Program.

$\mathrm{He}$ is the author of Magic in a Bottle, a history of drug research, and, with Dr. Lee as co-author, of Pills, Profits, and Politics. 
